\title{
Environmental Drivers of Free-Living vs. Particle-Attached Bacterial Community Composition in the Mauritania Upwelling System
}

\author{
Jennifer Bachmann 1,2*, Tabea Heimbach ${ }^{1,2,3}$, Christiane Hassenrück', \\ Germán A. Kopprio ${ }^{1}$, Morten Hvitfeldt Iversen ${ }^{4,5}$, Hans Peter Grossart ${ }^{6,7}$ and \\ Astrid Gärdes ${ }^{1}$
}

1 Leibniz Centre for Tropical Marine Research (ZMT), Bremen, Germany, ${ }^{2}$ Faculty of Biology and Chemistry (FB2), University of Bremen, Bremen, Germany, ${ }^{3}$ Max Plank Institute for Marine Microbiology, Bremen, Germany, ${ }^{4}$ Helmholtz Young Investigator Group SEAPUMP, Alfred Wegener Institute for Polar and Marine Research, Bremerhaven, Germany, ${ }^{5}$ Center for Marine Environmental Sciences (MARUM), University of Bremen, Bremen, Germany, ${ }^{6}$ Leibniz-Institute of Freshwater Ecology and Inland Fisheries (IGB), Berlin, Germany, ${ }^{7}$ Institute of Biochemistry and Biology, University of Potsdam, Potsdam, Germany

OPEN ACCESS

Edited by:

Chuanlun Zhang,

Southern University of Science and Technology, China

Reviewed by:

Stefan M. Sievert,

Woods Hole Oceanographic

Institution, United States

Eyal Rahav,

Israel Oceanographic and Limnological Research, Israel

*Correspondence:

Jennifer Bachmann Jennifer.bachmann@/eibniz-zmt.de; bynnej@gmail.com

Specialty section: This article was submitted to Aquatic Microbiology, a section of the journal

Frontiers in Microbiology

Received: 01 August 2018 Accepted: 05 November 2018 Published: 23 November 2018

Citation:

Bachmann J, Heimbach T,

Hassenrück C, Kopprio GA,

Iversen MH, Grossart HP and Gärdes A (2018) Environmental

Drivers of Free-Living vs.

Particle-Attached Bacterial

Community Composition

in the Mauritania Upwelling System.

Front. Microbiol. 9:2836.

doi: 10.3389/fmicb.2018.02836
Saharan dust input and seasonal upwelling along North-West Africa provide a model system for studying microbial processes related to the export and recycling of nutrients. This study offers the first molecular characterization of prokaryotic particleattached (PA; > $3.0 \mu \mathrm{m})$ and free-living (FL; 0.2-3.0 $\mu \mathrm{m})$ players in this important ecosystem during August 2016. Environmental drivers for alpha-diversity, bacterial community composition, and differences between FL and PA fractions were identified. The ultra-oligotrophic waters off Senegal were dominated by Cyanobacteria while higher relative abundances of Alphaproteobacteria, Bacteroidetes, Verrucomicrobia, and Planctomycetes (known particle-degraders) occurred in the upwelling area. Temperature, proxy for different water masses, was the best predictor for changes in FL communities. PA community variation was best explained by temperature and ammonium. Bray Curtis dissimilarities between FL and PA were generally very high and correlated with temperature and salinity in surface waters. Greatest similarities between FL and PA occurred at the deep chlorophyll maximum, where bacterial substrate availability was likely highest. This indicates that environmental drivers do not only influence changes among FL and PA communities but also differences between them. This could provide an explanation for contradicting results obtained by different studies regarding the dissimilarity/similarity between FL and PA communities and their biogeochemical functions.

\footnotetext{
Keywords: prokaryotes, biodiversity, microbial ecology, alpha diversity, Bray Curtis dissimilarity, temperature, salinity, 16S rRNA Illumina amplicon sequencing
}

\section{INTRODUCTION}

Bacteria and archaea, the unseen majority (Whitman et al., 1998), carry out important steps in the biogeochemical cycling of carbon and nutrients, and thus are pivotal for the functioning of marine ecosystems. Many heterotrophic bacteria hydrolyze particulate into dissolved organic matter (OM) (Azam and Malfatti, 2007), which is further hydrolyzed into small molecules for direct uptake by 
heterotrophic microorganisms. Furthermore, the microbial loop (Azam et al., 1983) converts waste products and other OM into bioavailable organic and inorganic nutrients and subsequently releases them into the surrounding water supporting new biomass production. Thereby, heterotrophic bacteria provide essential nutrients for phytoplankton primary production, which forms the base of any aquatic food web.

Generally, pelagic bacteria can be categorized as truly freeliving (FL), truly particle-attached (PA), and bacteria alternating between the two lifestyles (Grossart, 2010). The truly FL bacteria spend their whole life-cycle suspended in the water column, whereas truly PA bacteria remain predominantly associated with various sorts of particles. In contrast, alternating bacteria can constantly attach and detach from particles and hence move between both life-styles. These differences in life-styles are linked to metabolic differences, e.g., PA bacteria generally have a higher capacity to degrade polymeric OM than FL bacteria (Lyons and Dobbs, 2012). Therefore, it is important to distinguish between bacterial life-styles for a better understanding of bacterial community composition (BCC), dynamics, and functions in the ocean.

Particle-attached bacteria are involved in the degradation of sinking particulate OM and thereby affect the efficiency of the biological carbon pump: Previous studies have shown that microbial communities attached to sinking particles typically possess carbon-specific respiration rates of around 0.1-0.2 $\mathrm{d}^{-1}$ (Ploug et al., 1999). Hence, their respiration and activity can importantly reduce the amount of organic carbon that is exported to below the thermocline. In this context, it has since been recognized that the capacity for particulate $\mathrm{OM}$ degradation depends on the BCC (Enke et al., 2018). Additionally, it has been shown that sinking particles and their attached microbial communities contribute to the vertical connectivity of the BCC in the ocean (Mestre et al., 2018). Thus to understand the functional role of bacteria, knowledge on PA community composition is of profound importance in marine regions characterized by a high carbon export.

Eastern boundary currents, such as the Canary Current, are among the most productive marine regions of the world (Carr, 2002). By taking up large amounts of carbon, the Canary Current system plays an important role in the global export of organic carbon (Arístegui et al., 2009; Fischer et al., 2016). In the southern part of the Canary Current ecosystem, upwelling of nutrients along the coasts of Mauritania and Senegal supports global fisheries by providing suitable spawning grounds for many economically important fish species (Arístegui et al., 2009). Upwelling and surface currents in this region are influenced by changes in trade winds and the migration of the intertropical convergence zone toward the relatively warmer hemisphere between $2^{\circ} \mathrm{N}$ during boreal winter and $9^{\circ} \mathrm{N}$ during summer (Schneider et al., 2014). Additionally, Saharan dust input leads to the natural fertilization of this system (Fischer et al., 2009).

Despite the region's importance for fisheries and the global carbon cycle, the prokaryotic microbial community off the coast of Mauritania and Senegal has received little attention. Dinitrogen fixation by benthic cyanobacteria (Gier et al., 2017) and microbial methanol uptake (Dixon et al., 2013) have been assessed off Mauritania but only one CARD-FISH-based investigation of the whole BCC has been carried out further offshore (Thiele et al., 2015). They observed highest similarities between PA bacteria at depth and FL bacteria from the deep chlorophyll maximum (DCM). High particle export, frequent changes in the intensity of the year-round upwelling and the natural fertilization with Saharan dust (Fischer et al., 2016), render this region a model system for studying microbial processes related to the export and recycling of inorganic nutrients and carbon in the ocean.

Since the micro-scale heterogeneity varies among aquatic habitats, the distribution of specific bacterial species in the ocean is not uniform (Stocker, 2012), whereby the BCC depends on both abiotic (e.g., temperature, $\mathrm{pH}$, etc.) and biotic factors (e.g., algal blooms, zooplankton feces, etc.). It has been demonstrated that in general about $25 \%$ of the variation microbial community composition can be explained by environmental parameters (Hanson et al., 2012). Previous studies have correlated bacterial community structures with environmental parameters, such as salinity (Rieck et al., 2015), quantity and quality of inorganic nutrients and OM (Ortega-Retuerta et al., 2013), particle composition (although unsuccessfully; Zhang et al., 2016) as well as chlorophyll $a(\operatorname{chl} a)$ and temperature (Kan et al., 2006). FL and PA bacteria, however, seem to be differentially affected by bulk water parameters, e.g., the larger the particle, the more insensitive the attached community is to changes in abiotic water parameters (Yung et al., 2016). Thereby, the PA community was mainly influenced by substrate availability and particle quality (Yung et al., 2016). Very few studies have assessed the effects of the latter on the similarity/dissimilarity of FL and PA communities, and there has been some debate in the literature about whether FL and PA bacteria are generally similar (Hollibaugh et al., 2000; OrtegaRetuerta et al., 2013) or dissimilar (DeLong et al., 1993; Acinas et al., 1999; Rieck et al., 2015; Zhang et al., 2016).

Along the coastlines of Mauritania and Senegal natural horizontal and vertical gradients in environmental variables and substrate availability exist, rendering the North-West African coast an ideal models system for those studies. In the surface waters from Mauritania to Senegal, horizontal gradients of decreasing salinity and inorganic nutrients and increasing temperature result from riverine water discharge and precipitation. Vertically, substrate availability changes from the oligotrophic surface waters off Senegal, over the more productive DCM to $200 \mathrm{~m}$ depth, where life almost exclusively relies on sinking OM from the sunlit ocean. The DCM is a prevalent structure of tropical marine environments, occurs at around 20$100 \mathrm{~m}$ depth and is characterized by increased concentrations of chla. The DCM often coincides with high primary productivity as environmental conditions are ideal for phytoplankton growth (Eppley et al., 1988; Raimbault et al., 1993; Cullen, 2015). Thus, substrate availability for bacteria may be high at the DCM. However, so far the effect of substrate availability on the BCC in natural environments has received little attention. During the Meteor M129 cruise to the Golf d'Arguin (in Northern Mauritania) and Sine Saloum (Senegal, Figure 1) in July to August 2016, we investigated the BCC off Mauritania and Senegal and the effect of substrate availability on the similarity 


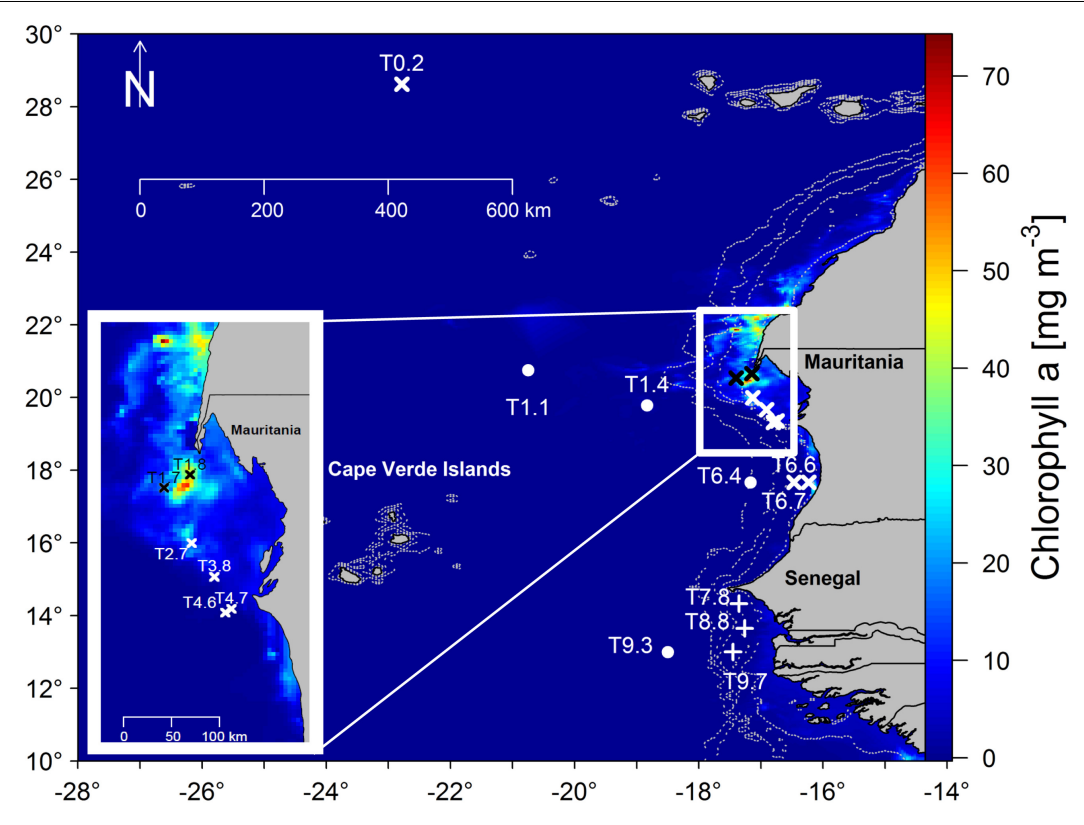

FIGURE 1 | Sampling stations for this project during M129. Sampling was carried out at 16 stations at the surface only (x) surface and DCM (+) and from surface, over DCM to $200 \mathrm{~m}$ depth (•). The figure in the lower left corner is an enlargement of the sampling region off Northern Mauritania. Stations T1.7 and T1.8 (black) were situated in the core of the upwelling area, while station T1.4 was within in an anticyclonic eddy. The map was produced from Level 3 Modis Aqua satellite imagery data on monthly chlorophyll a concentrations obtained from https://oceandata.sci.gsfc.nasa.gov/MODIS-Aqua/.

between FL and PA bacteria by addressing the following research questions:

1. What is the FL and PA microbial community composition off NW Africa, and which conclusions can we draw with regard to the role of PA bacteria in the degradation of organic particles?

2. What are the effects of environmental parameters and substrate availability on the similarity/dissimilarity of FL and PA bacterial communities in this region?

We hypothesize that bacteria, which are adapted to (ultra-)oligotrophic conditions, predominate off Senegal, while the upwelling and potential formation of phytoplankton blooms may stimulate taxa adapted to more mesotrophic conditions off the North-West African coast. Temperature is assumed to be the main environmental driver for changes in overall BCC, and we hypothesize that environmental factors, such as temperature, salinity, and substrate availability, also affect the differences between FL and PA communities, but to a different extent. As we expect the highest substrate availabilities at the depths of the DCM, we hypothesize that FL and PA communities will be most similar there.

\section{MATERIALS AND METHODS}

The M129 cruise started from the Azores, on July 30 and finished on the Cape Verdes on August 25, 2016. Sampling was carried out along several transects off the coast of Mauritania and Senegal (Figure 1). Sampling stations were distributed over different oceanic regions, including the shelf break and shallow $(<50 \mathrm{~m})$ waters closer to the coast. More information about the respective M129 cruise stations (see Supplementary Table 1) is available under https:// www.pangaea.de/ddi?retr=events/Meteor_1986/M129.retr\&conf =events/CruiseReportHTML.conf\&title=Station+list+of + cruise + M129\&format=html. Water samples were obtained using a SBE32 rosette water sampler with $24 \times 10 \mathrm{~L}$ Niskin bottles $(\mathrm{s} / \mathrm{n}$ 0342) from 16 stations over 3 depths: 16 surface samples (ca. $5 \mathrm{~m}$ ), 7 DCM samples, and 4 samples from $200 \mathrm{~m}$ depth (below the thermocline). Water samples were immediately filtered through a $125-\mu \mathrm{m}$ mesh in order to exclude larger organisms, such as zooplankton. The filtrate was collected in polyethylene canisters and processed under laboratory conditions within $2-3 \mathrm{~h}$.

Physicochemical parameters (temperature, salinity, chla, and turbidity) were measured in situ using the Rosette water sampler, which was equipped with a Seabird_electronics SBE9 CTD (s/n 0572) and a digiquartz pressure sensor (s/n 75760) using a double sensor setup.

\section{Chemical Parameters}

Particulate organic carbon (POC) samples were taken at all surface stations. Between 1000 and $5000 \mathrm{~mL}$ of marine water were filtered through pre-combusted $\left(450^{\circ} \mathrm{C}\right.$ for $\left.4 \mathrm{~h}\right)$ and preweighted $47 \mathrm{~mm}$ GF/F filters (Whatman, Dassel, Germany). Filters were dried at $40^{\circ} \mathrm{C}$ for at least $24 \mathrm{~h}$ and total carbon (TC) and total nitrogen (TN) concentrations were measured on an Elemental Analyzer (EA-3000, EuroVector, Italy). The organic carbon fraction ( $\mathrm{C}_{- \text {org }}$ or POC) was measured after acidification 
of the filter with $1 \mathrm{~N} \mathrm{HCl}$ to remove the inorganic carbon. $\mathrm{CN}$ ratios were calculated from $\mathrm{C}_{-}$org and $\mathrm{TN}$.

Dissolved inorganic nutrient (NUT) samples were taken in technical triplicates from the POC filtrate and frozen at $-20^{\circ} \mathrm{C}$ until analysis on board. Using a continuous segmented flow autoanalyzer (San System, Skalar, Netherlands) the concentrations of five NUT, i.e., nitrate, nitrite, ammonium, phosphate, and silicate, were determined after Grasshoff et al. (1999).

Technical triplicates of dissolved organic carbon (DOC) concentrations were also obtained from the POC filtrate and preserved frozen at $-20^{\circ} \mathrm{C}$. Acidified DOC samples were analyzed using the high-temperature combustion method (Dafner and Wangersky, 2002) with a TOC-VCPH autoanalyzer (Shimadzu, Mandel, Canada).

\section{Plankton Counts}

Plankton samples for quantitative analysis were taken at selected surface (T1.1, T0.2, T3.8, T1.4, T4.6, T8.8), DCM (T1.1, T1.4, T7.8, T9.3), and $200 \mathrm{~m}$ stations (T1.1, T9.3). Samples were filtered through a $125-\mu \mathrm{m}$ mesh in order to remove larger organisms and fixed with formalin ( $2 \% \mathrm{v} / \mathrm{v}$ final concentration). For analysis, $100 \mathrm{~mL}$ of the fixed sample were filled into an Utermöhl chamber. Cells were counted after overnight sedimentation at $400 \times$ magnification and across 50 random fields. The identified cells were classified into the following plankton groups: diatoms, haptophytes, dinoflagellates, non-flagellated chlorophytes, and other flagellates.

\section{Bacterial Enumeration}

Water samples $(50-150 \mathrm{~mL})$ were fixed with formaldehyde (2\% $\mathrm{v} / \mathrm{v}$ ) and stored at $4^{\circ} \mathrm{C}$ for $48 \mathrm{~h}$. PA and FL bacteria were separated via sequential filtration through 3.0 and $0.2 \mu \mathrm{m}$ (Kegler et al., 2017) Nuclepore TrackEtch polycarbonate membranes (Whatman, Dassel, Germany), respectively. Filters were air-dried and frozen until microscopic analysis (Rieck et al., 2015). 4',6Diamidino-2-phenylindole (DAPI; Thermofisher Scientific Inc., Waltham, MA, United States) was diluted in a 3:1 mounting solution (made of Citifluor AF mounting medium; Citifluor Ltd., London, United Kingdom) and Vecta shield (Vector Laboratories Inc., Burlingame, CA, United States) to a concentration of $1 \mu \mathrm{g} \mathrm{mL}^{-1}$. The DAPI/mounting medium solution was directly added onto the filter. FL bacteria were enumerated by using an automatic microbial cell enumeration system. A multipurpose fully automated microscope imaging system (MPISYS) was used for the refined image acquisition. Image selection, cell determination, and enumeration were carried out using the ACMEtool2.0 (Bennke et al., 2016). PA bacteria were manually enumerated with an epifluorescence microscope "Axioskop 40" (Zeiss, Jena, Germany) at $1000 \times$ magnifications (Grossart et al., 2005). A minimum of 40 grids (grid size: $15,625 \mu \mathrm{m}^{2}$ ) was counted.

\section{Molecular Analysis of the Microbial Community}

FL and PA bacteria were separated as described under "Bacterial enumeration" (for filtered volumes see
Supplementary Table 2). Filters were frozen on board and transported at $-80^{\circ} \mathrm{C}$. Storage at the ZMT until further processing was at $-20^{\circ} \mathrm{C}$. DNA extraction was carried out after Nercessian et al. (2005). Briefly, the phenol-chloroformisoamylalcohol extraction protocol was adapted for planktonic bacteria as previously proposed by Rieck et al. (2015). Cetyltrimethyl ammonium bromide (CTAB) was used as a complexing agent for polymeric substances. For all samples, the second chloroform-isoamylalcohol washing treatment was skipped. DNA extracts were sent to LGC genomics (Berlin, Germany) for amplicon sequencing of the microbial community. The primer pair Bakt_341F (5'-TCCTACGGGGGCWGCAG-3') and Bakt_805R (5'-TGACTACHVGGGTATCTAAKCC-3') was used to target the hypervariable regions V3-V4 of the bacterial 16S rRNA gene (Klindworth et al., 2013). Sequencing was performed on an Illumina MiSeq using V3 Chemistry (Illumina) in a $2 \times 300$ base pair paired-end run.

\section{Bioinformatic Analyses}

Demultiplexing and the removal of primer sequences from the raw paired-end reads with cutadapt (Martin, 2011) were performed by LGC genomics. Sequences were further analyzed according to Hassenrück et al. (2016): Sequences were quality trimmed with a sliding widow of four bases and an average quality of 15 using trimmomatic v.033 (Bolger et al., 2014). Using PEAR v0.9.6 (Zhang et al., 2014), sequences were merged, and swarm v2.1.1 was applied to cluster operational taxonomic units (OTUs) (Mahé et al., 2014). Taxonomic classification with SILVA 128 was carried out using the SILVA-ngs pipeline (Quast et al., 2013). Singletons, doubletons, chloroplasts, mitochondria, and OTUs unclassified on phylum level were excluded.

Based on the 16S gene of the chloroplast the presence/absence of eukaryotic phytoplankton genera was inferred (Schmidt et al., 1991; Needham et al., 2017). Chloroplast 16 S sequences were aligned against a customized reference database only containing chloroplast sequences from cultivated organisms obtained from the NCBI refseq database (date accessed: June 27, 2017). Sequences with $>93 \%$ similarity were filtered out for further analysis and the taxonomic path for the best hit was extracted. A detection threshold of at least 10 sequences was chosen to ensure that the sequenced chloroplasts were really present. Omission of non-phytoplankton lineages and manual curation of the taxonomic path ensured optimal phytoplankton characterization based on the $16 \mathrm{~S}$ region of chloroplasts.

\section{Data Archiving}

In compliance with the Minimal Information about any (X) Sequence (MIxS) standard (Yilmaz et al., 2011), the raw data of demultiplexed and primer-clipped sequences were deposited at the European Nucleotide Archive (ENA; Toribio et al., 2017) using the data brokerage service of the German Federation for Biological Data (GFBio; Diepenbroek et al., 2014). They are accessible under PRJEB26997. 


\section{Statistical Analyses}

All statistical analyses were run in $\mathrm{R}$ studio using the core distribution (R-Core-Team, 2015) and additional packages, such as vegan (Oksanen et al., 2015) and gplots (Warnes et al., 2016).

Environmental parameters were displayed in a principal component analysis (PCA). The three missing values of turbidity, fluorescence, and $\mathrm{O}_{2}$ were substituted by the means of all other samples of the respective parameter. Based on the PCA, the samples were classified into one of the following categories: surface upwelling (Sur-UW), surface oligotrophic (Sur-oligo), DCM, $200 \mathrm{~m}$, as well as eddy surface (Eddy-sur), eddy DCM (Eddy-DCM), and Eddy-200 m samples. Eddy samples were too different from the others in the respective category but since only one eddy was sampled the Eddy categories had to be excluded from any statistical analyses.

PERmutational Multivariate Analysis Of Variance (PERMANOVA) and Analysis Of SIMilarity (ANOSIM) based on Jaccard dissimilarity were used to test for differences in phytoplankton presence/absence between the categories.

Differences between FL and PA bacterial cell numbers and alpha diversity were assessed with paired $t$-tests. Alpha diversity was assessed using the Inverse Simpson Index calculated without prior rarefying to equal library sizes as rarefaction curves based on this index were saturated at the obtained sequencing depths (Chao et al., 2014). To test for significant differences in alpha diversity among FL and PA, two alternatives were tested: (i) differences occurring between categories of samples identified in the PCA using ANOVA and if applicable Tukey's test, and (ii) correlation with environmental parameters using a linear model. For all regression-based analyses, collinearity between predictor variables was checked and avoided so that only temperature, salinity, fluorescence, ammonium, and DOC remained.

Pairwise BC dissimilarities were used for cluster analysis (unweighted pair-group method using arithmetic average, UPGMA). Ordination of similarities within each separate fraction was carried out using non-metric multidimensional scaling (NMDS) on relative abundances of FL and PA OTUs. In order to test differences in beta diversity trends between FL and PA, a Procrustes analysis was run on these NMDS ordinations.

Redundancy analysis (RDA) was performed with centered log-ratio-transformed sequence counts of both FL and PA fractions, separately. Variation partitioning was used to assess the contribution of each of the environmental parameters in the RDA models, while accounting for the variability explained by the others (pure effects). Forward model selection was conducted to identify the best-fitting RDA models based on the minimum Akaike Information Criterion (AIC).

\section{RESULTS}

\section{Physical and Chemical Environmental Parameters}

Physicochemical environmental parameters were ordinated in a PCA (Figure 2) and all raw values are archived at PANGAEA ${ }^{1}$

\footnotetext{
${ }^{1}$ https://doi.pangaea.de/10.1594/PANGAEA.889977
}

and Supplementary Table 1. In the PCA, the first two principal components explained $62 \%$ of the variability in the data set. PC1 was mainly influenced by nutrients (except for ammonium), which were positively correlated with $\mathrm{PC} 1$, and physico-chemical parameters related to different water masses, which showed a negative correlation with this PC. PC1 was an indicator for water depth, generally ordinating the deeper stations, which were colder and richer in nutrients, in the positive range. Apart from three upwelling stations (T1.8, T2.7, and T3.8) all surface stations, characterized by higher temperatures and lower nutrients, clustered in the negative range of PC1. PC2 was an indicator for upwelling and was positively correlated with fluorescence and turbidity, as well as DOC and ammonium, i.e., variables indicating productivity.

Three of the four $200 \mathrm{~m}$ samples clustered closely together. T1.1 was not grouped closely with the other $200 \mathrm{~m}$ samples, indicating its origin from a different water mass. An oxygen minimum with $7 \mu \mathrm{mol} \mathrm{L}^{-1}$ at $30 \mathrm{~m}$ depth, the direction of rotation and density structure (obtained from CTD profiles and acoustic doppler current profiler; data unpublished) suggested that station T1.4 was located within an anticyclonic mode water eddy (ACME). The Eddy-DCM station was very different from the remaining loosely clustering DCM stations. At station T1.4, turbidity and fluorescence were highest $\left(0.2\right.$ and $6.1 \mathrm{mg} \mathrm{m}^{-3}$, respectively) among all DCM samples and were within the range of the Sur-UW samples. Station T1.4 also had the highest N:P ratio (14.5) while all other DCM stations showed ratios between 2 and 12.7 .

Six surface stations were characterized by elevated chla concentrations (Figure 1) together with nitrate concentrations of $>2 \mu \mathrm{M}$ and were thus categorized as upwelling samples. Station T2.7 was found on the projectory line of the ammonium vector because it had the highest ammonium concentration of all stations (Figure 2). Temperatures of the Sur-oligo stations were warmer and increased from Mauritania (approximately $23^{\circ} \mathrm{C}$ ) toward Senegal (approximately $29^{\circ} \mathrm{C}$ ). Salinities of Suroligo stations ranged from 35 to 37.1 with the lowest and highest values off Senegal (T3.9) and offshore off Mauritania (T0.2), respectively.

Neither of the Sur-UW nor the Sur-oligo surface samples had N:P ratios (all <11) close to Redfield ratio. Nutrient concentrations indicated that the upwelling stations were at most mesotrophic and Sur-oligo stations were oligo- to ultraoligotrophic.

\section{Phytoplankton Composition}

Microscopic analysis (Supplementary Figure 1) of phytoplankton communities at 14 out of 27 samples revealed concentrations between 10,400 cells $\mathrm{L}^{-1}$ (at T1.1 $200 \mathrm{~m}$ ) and more than $10^{6}$ cells $\mathrm{L}^{-1}$ (at the Eddy surface station T1.4). The lowest surface numbers were observed at T1.1 with approximately 20,000 cells $\mathrm{L}^{-1}$. In general, cyanobacteria and haptophytes were the dominant phytoplankton groups in this area. Diatom cell numbers did not exceed 45,000 cells L $^{-1}$ but were the most diverse phylum (with 20 genera). They included, e.g., Thalassiosira and Chaetoceros. Emiliania and Phaeocystis were the only two detected genera of haptophytes. 


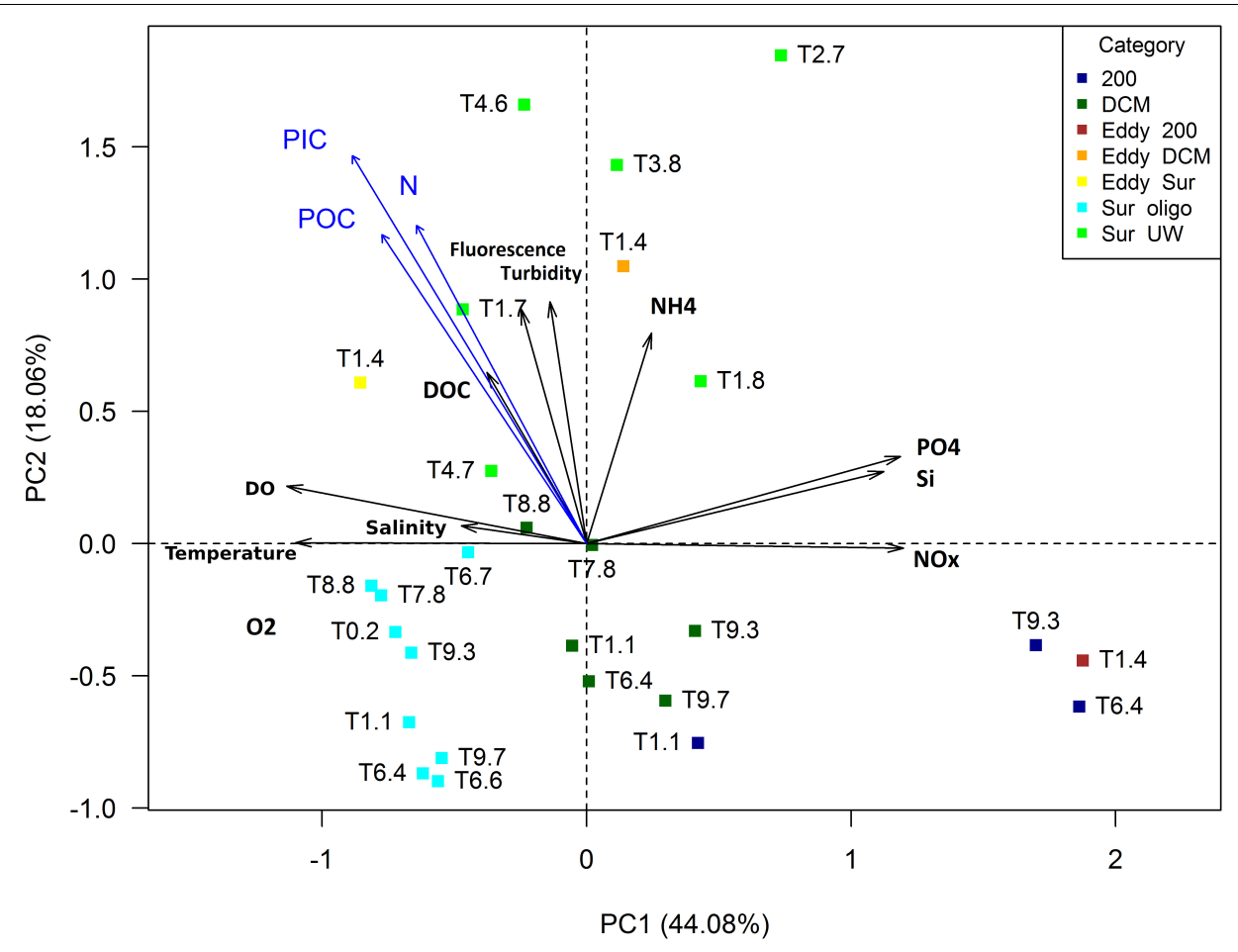

FIGURE 2 | Principal component analysis (PCA) of environmental variables measured at the sampling stations (type II scaling). Particulate organic/inorganic carbon (POC/PIC) and particulate nitrogen (N) concentrations were only available from surface waters. They were added to the PCA using envfit. DO, dissolved oxygen.

The presence/absence of phytoplankton genera based on chloroplast sequences (Supplementary Figure 2) indicated spatial trends over the sampling area: Few to no genera were found in the $200 \mathrm{~m}$ samples. Upwelling samples clustered together in the heat map, indicating similar phytoplankton communities. Phytoplankton counts at the two Sur-UW stations T3.8 and T4.6 revealed that coccolithophores followed by diatoms and other flagellates were the dominant plankton groups in these samples. Although the classification of samples into the four sample categories was able to significantly explain a small proportion of phytoplankton community variation (PERMANOVA, $\left.F_{(2,21)}=1.84, R^{2}=0.15, p=0.032\right)$, this effect was not sufficient to result in well-separated communities (ANOSIM, $R=0.05, p=0.3$ ).

\section{Cell Numbers of Bacterial Fractions}

Abundances of FL bacteria were two to three orders of magnitude higher than those of PA (Figure 3). A paired $t$-test confirmed significant differences between FL and PA bacterial abundances (paired $t$-test: $t=8.95, d f=26, p<0.001$ ). Lowest cell numbers (Figure 3) were generally found in the $200 \mathrm{~m}$ samples, although the increase of cell numbers toward the surface stations was more pronounced in the FL fraction. Highest FL cell numbers $\left(>4 \times 10^{6}\right.$ cells $\left.\mathrm{mL}^{-1}\right)$ were found at the coastal and nutrient-rich Sur-UW station T3.8. The lowest PA numbers, with $<3000$ cells $\mathrm{mL}^{-1}$, were measured at the deep T1.1 $200 \mathrm{~m}$ and the saline T0.2 offshore stations, while highest PA bacterial abundances $\left(>9 \times 10^{5}\right.$ cells $\left.\mathrm{mL}^{-1}\right)$ were found at the more nutrient-rich and coastal surface stations T4.6 and T4.7.

\section{Alpha Diversity of Bacterial Fractions}

No significant differences in alpha diversity were found between FL and PA (paired $t$-test: $t=-1.07, d f=26, p=0.3$ ). In both fractions, alpha diversity tended to increase with depth. Lowest alpha diversity was found in the Sur-oligo samples. The categories significantly explained underlying patterns in alpha diversity of both FL (ANOVA, $F_{(3,20)}=7.79, p=0.001$ ) and PA bacteria (ANOVA, $F_{(3,20)}=8.35, p<0.001$ ). Multiple pairwise comparisons indicated that the alpha diversity of FL bacteria at $200 \mathrm{~m}$ was significantly different from all other categories (Supplementary Table 3), while in the PA fraction only $200 \mathrm{~m}$ and surface communities differed in alpha diversity (Supplementary Table 4). Temperature was identified as the best predictor for explaining differences in alpha diversity in the FL (ANOVA, $\left.F_{(1,22)}=22.32, p<0.001\right)$ and PA fraction (ANOVA, $\left.F_{(1,22)}=8.58, p=0.008\right)$.

\section{Bacterial Community Composition (BCC)}

The most common bacterial phyla in this study were Proteobacteria (42\%), Cyanobacteria (20\%), Bacteroidetes (15\%), Actinobacteria (12\%), Planctomycetes (5\%), Verrucomicrobia (2\%), and Marinimicrobia (1.8\%).

Actinobacteria, especially the OM1 clade, were typically found among the FL bacteria and shifted from the OM1 group (present in surface and DCM samples) to the family Sva0996 marine group 

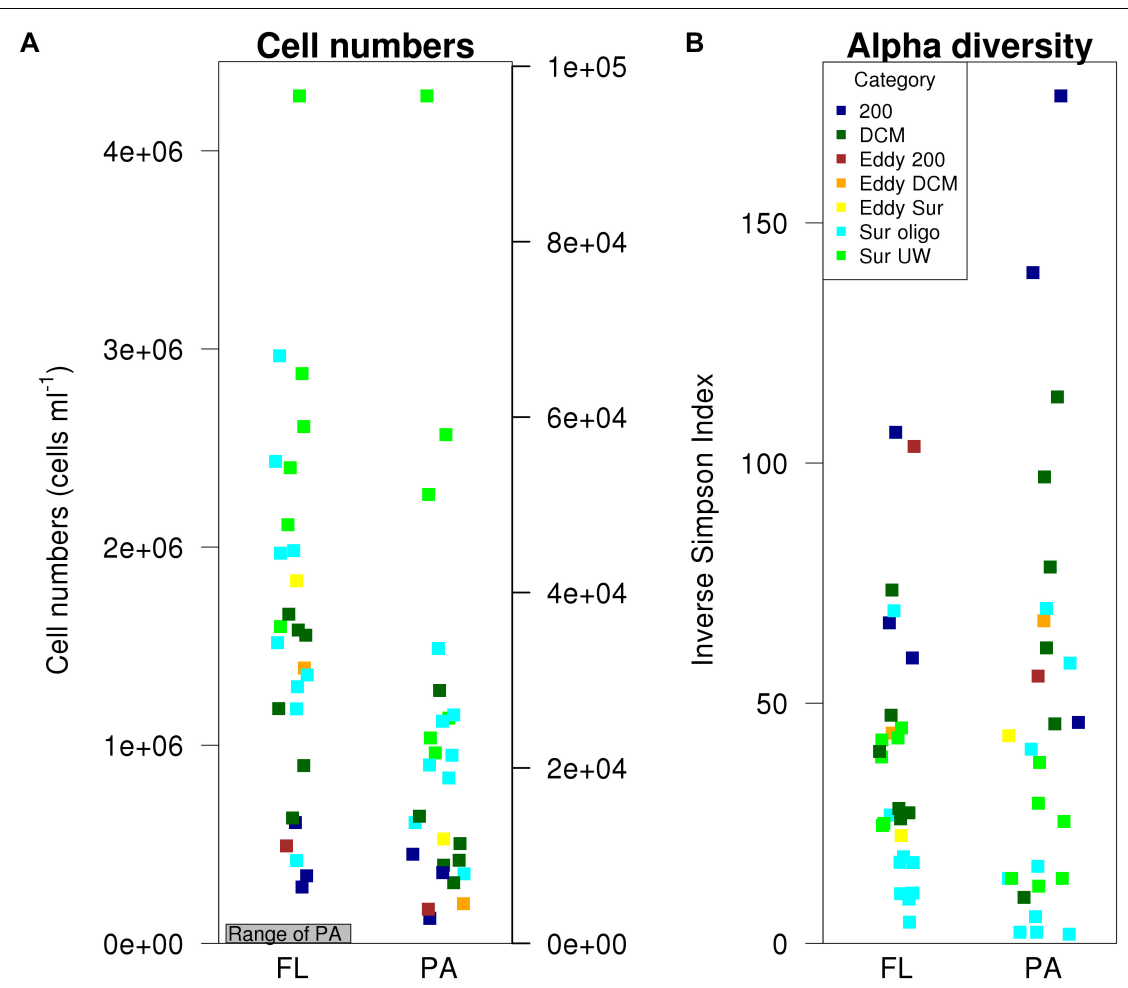

FIGURE 3 | FL and PA cell numbers and inverse Simpson index.

\section{Free-living}
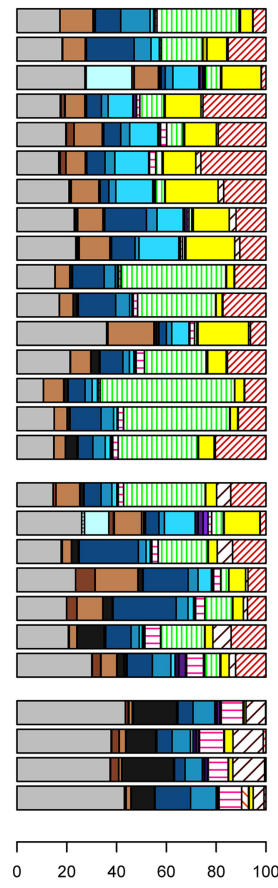

Sequence proportion [\%]

\section{Particle-attached}

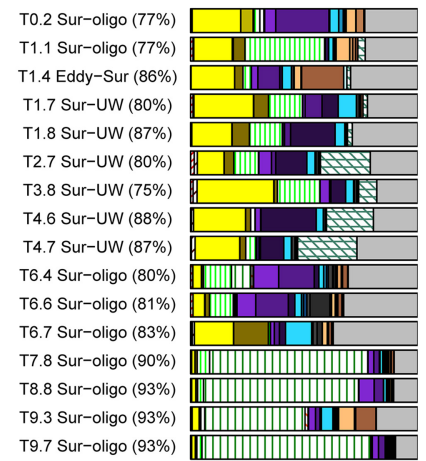

T1.1 DCM (68\%)

T1.4 Eddy-DCM $(79 \%)$

T6.4 DCM (75\%)

$\mathrm{T7} .8 \mathrm{DCM}(89 \%)$

T8.8 DCM (86\%)

T9.3 DCM $(80 \%)$

T9.7 DCM (27\%)

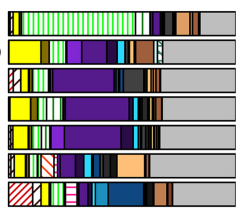

T1.1 $200(83 \%)$

T1.4 Eddy-200 (90\%)

T6. $4200(90 \%)$

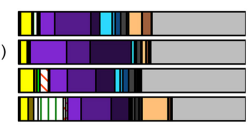

$\square$ Actinobacteria

VOM1 clade

QSva0996 marine group

Bacteroidetes

$\square$ Flavobacteriaceae

$\square$ NS7 marine group

$\square$ Saprospiraceae

$\square$ Cyanobacteria

Iㅔ]Subsectionl_Familyl

IIISubsectionIII_Familyl

$\square$ Firmicutes

NClostridiaceae 1

$\square$ Marinimicrobia (SAR406 clade)

目Marinimicrobia (SAR406 clade)

$\square$ Planctomycetes

$\square$ OM190

$\square$ Phycisphaeraceae

Planctomycetaceae $\square$ Alphaproteobacteria

$\square$ Rhodobacteraceae

$\square$ Rhodospirillaceae

Surface 1

$\square$ Deltaproteobacteria

Bdellovibrionaceae

Oligoflexaceae

SAR324 clade(Marine group B)

$\square$ Gammaproteobacteria

$\square$ Alteromonadaceae

$\square$ HTA4

$\square$ SAR86 clade

$\square$ Vibrionaceae

ZD0405

Verrucomicrobia

$\square$ R76-B128

Verrucomicrobiaceae

other

$\square$ other

FIGURE 4 | Taxonomic compositions (family level) of FL and PA bacteria. Bray Curtis dissimilarity coefficients are given in brackets. 
at $200 \mathrm{~m}$ (Figure 4). Bacteroidetes, mainly Flavobacteriaceae and Alphaproteobacteria, occurred in both FL and PA fractions. Bacteroidetes dramatically decreased in their relative abundances with depth, especially in the PA fraction off the coast of Senegal. Cyanobacteria had high relative abundances in the surface stations off Senegal. Different types of cyanobacteria dominated the FL and PA communities in the surface stations off Senegal. The FL fraction contained high relative abundances of cyanobacteria belonging to subsection I (e.g., Synechococcus and Prochlorococcus), while the PA fraction was largely dominated by cyanobacteria belonging to subsection III (mainly Oscillatoria). The relative abundances of Cyanobacteria decreased with increasing depth. Marinimicrobia and Planctomycetes tended to increase with depth in the FL and PA fraction, respectively. The family Planctomycetaceae was enriched in the Sur-UW samples, while other families of the same phylum prevailed in the remaining samples (Figure 4). Rhodobacteraceae and Flavobacteriaceae increased in relative abundances in the FL fraction of the upwelling samples. Gammaproteobacteria were represented in both FL and PA fractions, although with different families. Deltaproteobacteria had higher relative abundances at $200 \mathrm{~m}$ compared to the surface samples. The highest relative abundances of Verrucomicrobia in this study were found in the Sur-UW samples (from T2.8 to T4.7).

\section{Beta Diversity and SIMPER}

Unweighted pair-group method using arithmetic average (Supplementary Figure 3) clearly separated FL and PA communities with the exception of one PA sample (T9.7-DCM), which clustered with the FL fraction. Pairwise Bray Curtis dissimilarities between $67 \%$ and $93 \%$ confirmed that FL and PA communities were generally very different. In particular, OTUs of Actinobacteria (OM1 clade) and Cyanobacteria [Prochlorococcus, Synechococcus (both FL), and Oscillatoria (PA fraction)] contributed to the observed differences between FL and PA communities at the surface (Supplementary Figure 4). Off the coast of Senegal (T7-T9) they explained between $40 \%$ and $60 \%$ of the detected dissimilarity, while off Mauritania they explained less. Dominance of individual OTUs decreased (as alpha diversity increased) with depth. OTUs of Delta- and Gammaproteobacteria were found among the OTUs explaining the detected differences at depth.

Procrustes analysis carried out on separate NMDS ordinations of FL and PA communities (Supplementary Figures 3B,C) suggested that although FL and PA communities might consist of different taxa, their beta diversity patterns were congruent (correlation $=0.8 ;$ m12 squared $=0.3529 ; p=0.001)$.

\section{Environmental Drivers Shaping $\mathrm{FL}$ and PA Bacterial Communities}

The RDA model only using temperature as predictor variable was best suited to explain differences in BCC for the FL fraction $\left(\mathrm{RDA}, \mathrm{AIC}=202.79\right.$, adjusted $\left.R^{2}=0.24, F_{(1,22)}=8.24, p=0.001\right)$. For PA bacteria, temperature [adjusted $R^{2}=0.082, F_{(1,21)}=3.07$, $p=0.001$ ] and ammonium [adjusted $R^{2}=0.056, F_{(1,21)}=2.41$, $p=0.001]$ significantly explained the underlying patterns [RDA, adjusted $\left.R^{2}=0.131, F_{(2,21)}=2.74, p=0.001\right]$.

Pairwise Bray Curtis dissimilarity coefficients were used to assess changes in the differences between FL and PA communities among categories and environmental parameters. Although insignificant (Kruskal-Wallis, $\mathrm{X}^{2}=3.45, d f=2$, $p$-value $=0.18$ ), there was a trend indicating changes in Bray Curtis dissimilarities between FL and PA communities with depth (Figure 5A): While PA and FL communities were most similar at the DCM, Bray Curtis dissimilarities increased to around $90 \%$ at $200 \mathrm{~m}$, suggesting major differences between PA and FL communities in deeper water masses. Among surface samples, differences in Bray Curtis dissimilarities existed, even though the surface categories did not explain the underlying changes. While we had insufficient statistical power to test for any significant correlations (Figure 5D), there was an indication that temperature and salinity correlate with surface Bray Curtis dissimilarities (Figures 5B,C). Especially, Bray Curtis dissimilarities of surface oligotrophic samples alone had higher correlations with both salinity $(r=-0.77)$ and temperature $(r=0.83)$. Collinearity between temperature and salinity was low $(r=-0.29)$ but there was a correlation between $\mathrm{NO}_{\mathrm{x}}^{-}$and temperature $(r=-0.73)$ among the surface samples.

\section{DISCUSSION}

This study provides the first detailed phylogenetic characterization of the BCC off the coast of Mauritania and Senegal. Knowledge about the BCC and especially the PA fraction is the basis for further studying and understanding microbial processes related to the export and recycling of $\mathrm{OM}$ in this economically important upwelling system. Our results indicated that differences between FL and PA bacterial communities were simultaneously influenced by environmental parameters and substrate availability.

\section{Environmental Variables, Phytoplankton, and Bacterial Communities Differ in the Upwelling Region}

Surface upwelling and (ultra-)oligotrophic sampling stations have been differentiated using chla and nitrate concentrations. During the boreal summer/autumn, upwelling off NW Africa only occurred North of $21^{\circ} \mathrm{N}$ as supported by satellite imagery (Figure 1) during our sampling campaign, and water masses most likely had a South Atlantic origin (Schütte et al., 2016). Stations T1.7 and T1.8 were situated at the southernmost tip of the upwelling region. Stations T2.8, T3.8, T4.6, and T4.7 were further south, but due to similar fluorescence values to T1.7 and T1.8, they were also characterized as upwelling samples. Dust input is also an important nutrient source, especially of phosphorous, iron, and other micro- and macronutrients, in this region (Bory and Newton, 2000; Iversen et al., 2010; Lekunberri et al., 2010; Pohl et al., 2011) and may have contributed to elevated nutrient concentrations. The remaining surface samples were characterized by lower fluorescence values. Increasing temperatures (distance to cold upwelling water and proximity to 
A

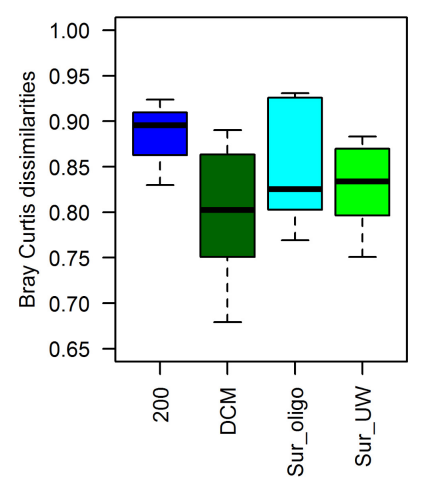

B

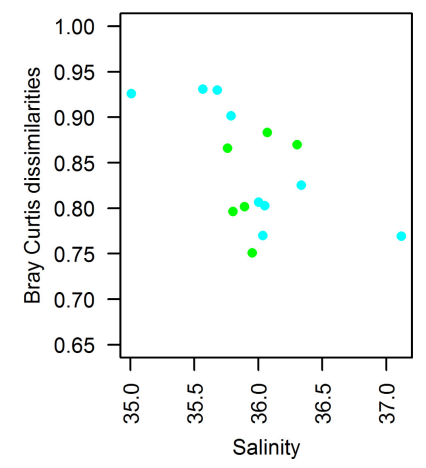

C

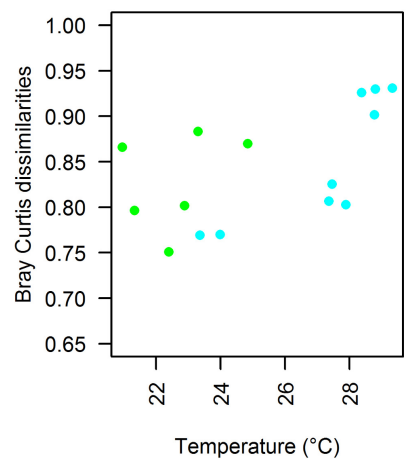

D

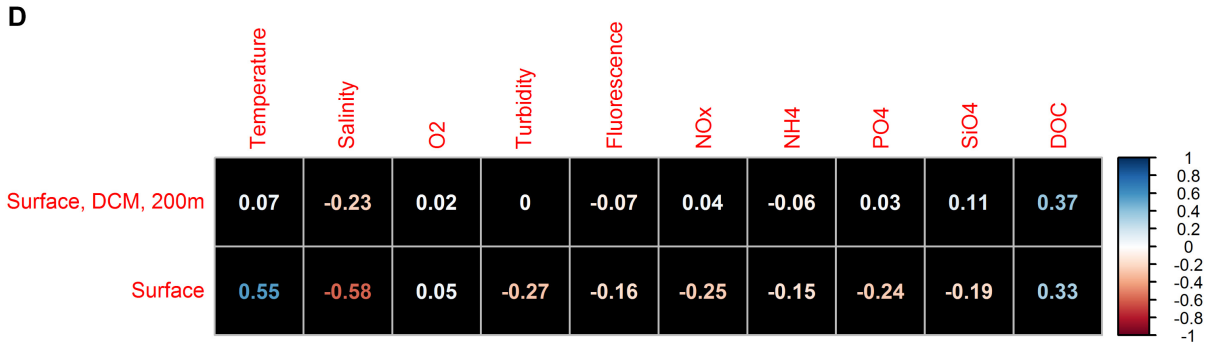

FIGURE 5 | Patterns of pairwise Bray Curtis dissimilarities between FL and PA communities: Differences between sample categories (A), correlation with salinity (B) as well as temperature (C) for surface samples (especially Sur-oligo), correlation with all observed environmental parameters (D).

equator) and decreasing salinity (heavy rainfall and proximity to river discharge) occurred from North to South. These Sur-oligo samples have diverse origins, from offshore waters off Mauritania to coastal waters off Senegal.

Phytoplankton communities were dominated by cyanobacteria and coccolithophores, with diatoms peaking at the upwelling stations and T0.2. The dominance of generally tiny phytoplankton cells (coccolithophores and cyanobacteria) may result from low silicate concentrations (Fischer et al., 2009) combined with the oligotrophic conditions, in which smaller cells have an advantage by being able to take up nutrients more efficiently than larger cells (Irwin et al., 2006). The bacterial communities in the ultra-oligotrophic waters off Senegal were characterized by higher relative abundances of Cyanobacteria. There, the ability to fix nitrogen may give cyanobacteria competitive advantages (Carpenter and Price, 1976).

The BCC in the upwelling area off Mauritania was dominated by Alphaproteobacteria, Bacteroidetes, Planctomycetes, and Verrucomicrobia. Planctomycetes, Verrucomicrobia, and some Bacteroidetes (e.g., Winogradskyella) are known to be particledegraders and can therefore be expected to represent key players in the recycling of carbon and other nutrients. The bacterial communities in ultra-oligotrophic waters off Senegal were characterized by higher relative abundances of Cyanobacteria. Additionally, low nutrient conditions and light may have stimulated the growth of FL proteorhodopsin-containing Flavobacteria (Williams et al., 2012). Together, this may explain why Bacteroidetes are present in both fractions (although represented by different genera) and why they tend to occur at higher relative abundances only in surface waters.

\section{FL and PA Communities Are Influenced by Environmental Parameters}

Many studies have demonstrated a significant correlation between BCC and environmental parameters (Hanson et al., 2012 and references therein). In this study, temperature in combination with ammonium or alone was able to explain around $13-24 \%$ of PA and FL community variation, respectively. This is in line with previous studies, which suggest that globally temperature is the most important factor for shaping bacterial community structure in epipelagic layers (Sunagawa et al., 2015). The results of our study also indicate that a higher proportion of FL variation can be explained by environmental parameters (in this case temperature) compared to PA bacteria. This can be expected as particles, to which PA bacteria are attached, may act as a "buffer" or micro-island (Lyons et al., 2010; Yung et al., 2016), while FL cells are more directly exposed to the surrounding water. Thereby, the size of the particle is important, because the larger the particle, to which bacteria attach, the more insensitive the bacteria might be to changes in the surrounding water (Yung et al., 2016). Additionally, the high density of bacteria on particles can lead to efficient signaling and quorum sensing (Gram et al., 2002), and nutrient ratios within particles may be 
very different from those in the surrounding sea water. All these factors may explain why PA bacteria are less affected by changes in environmental parameters than FL bacteria.

\section{How Can Environmental Parameters Influence the Similarity/Dissimilarity of FL and PA Bacteria?}

In this study two environmental parameters, temperature and salinity correlated with changes in Bray Curtis dissimilarities between FL and PA communities; especially when the surface upwelling samples (T1.7-T4.7; Figure 1) influenced by deeper water masses were excluded, and only Sur-oligo samples were taken into account. This correlation may be related to a steady temperature increase toward the equator and lower salinities due to heavy rain fall and riverine water input off Senegal. This in turn may have stimulated the genus Oscillatoria, which occurred at high relative abundances in the PA fraction off Senegal. Oscillatoria are found at intermediate salinities and are actually filamentous bacteria (Tomitani et al., 2006). While they may be PA, we suggest that they rather represented the particles themselves in this study as we observed filaments in the waters off Senegal, which were visible with the naked eye. This could even suggest that the filamentous bacteria were Trichodesmium, which are part of Oscillatoria. It has been observed previously that salinity can affect the differences between PA and FL communties, although in contrast to our results, these observations indicated higher similarities as salinity decreased (Ortega-Retuerta et al., 2013). This suggests that salinity may affect the extent to which PA and FL differ. Whether oligohaline vs. marine conditions render the two fractions more similar or dissimilar may, however, also depend on other factors.

\section{How Can Substrate Availability Affect the Similarity/Dissimilarity of FL and PA Bacteria?}

Our results show a trend, indicating that over depth, the Bray Curtis dissimilarities between FL and PA are lowest at the DCM. Although with a cruder method (CARD-FISH), focusing on larger particles, and a different depths resolution, Thiele et al. (2015) confirmed that aggregate-attached communities are most similar to the FL communities at the DCM in the same region but further offshore.

In our study both chla and nutrient concentrations were elevated at the DCM. This suggests a higher substrate availability for PA and FL bacteria when compared to the oligotrophic surface stations (upwelling stations are left out because they are influenced by DCM waters) and $200 \mathrm{~m}$ depth stations. PA bacteria have developed different strategies to survive and thrive, and substrate colonization and resource utilization can be very complex. It has been shown that the type of particle substrate and subsequent trophic interactions during its degradation drive the succession of bacteria on particles (Datta et al., 2016). Additionally, a trade-off between colonization and dispersal of two populations of the same species of bacteria has been unraveled (Yawata et al., 2014). This indicates that PA bacteria can have different strategies to exploit the particle resources. While some are adapted to firmly attaching to a particle to thrive in this new microenvironment as best as possible, others remain flexible in order to detach and move to a new hotspot if they receive luring cues. Among others, these two publications have demonstrated the role that the available substrate plays for primary colonization and how important motility can be for some bacteria to access new particles. Under conditions with high substrate availability (as, e.g., prevalent at the DCM) moving between particle hotspots could happen more frequently and could thereby render the PA and FL community more similar. In this context the occurrence of motile PA bacteria in the FL fraction would not imply a specialization for the FL fraction, but would rather stem from their tendency to migrate between hotspots (Yawata et al., 2014).

However, also other reasons are imaginable. For example, high substrate availability at the DCM might be a cue for some PA to detach before they are exported to the deeper oceans, allowing them to stay in the surface layer. Only future studies can elucidate these hypotheses further, but as the life-styles of bacteria coincide with functional differences and therefore implications for biogeochemical cycling, it is worth investigating this topic in more detail.

\section{CONCLUSION}

This study provides the first detailed description of the BCC off the coasts of Mauritania and Senegal. As this region is not only important for global fisheries but also responsible for a large draw down of carbon, our study is vital for a better understanding of the ecosystem function in this area. The high relative abundances of several groups of Planctomycetes, Verrucomicrobia, and some Bacteroidetes (e.g., Winogradskyella) indicated that these microbes may represent key players in the recycling of carbon in this area. Our results can serve as a basis for future research aimed directly at microbial processes related to the export and recycling of OM in the Mauritania upwelling area.

We have demonstrated the importance of systematically distinguishing between FL and PA communities, as the two fractions can be very different in abundance and functionality. Differences between FL and PA bacteria in oligotrophic surface samples correlate with changes in salinity and temperature and the prevalent conditions off Senegal promoted the growth of Oscillatoria. Similarities between FL and PA bacteria were highest at the DCM and may suggest that high substrate availability reduces the dissimilarity of the two fractions. This calls for further studies on the influence of environmental parameters and substrate availability on the similarity and dissimilarity between FL and PA fractions of heterotrophic bacteria and their respective biogeochemical functions.

Our study provides a valuable basis for future studies, which should focus on seasonal changes in microbial community structure and related biogeochemical function as well as changes in the similarity/dissimilarity of FL and PA as the upwelling region expands and contracts within the Mauritania upwelling area. 


\section{DATA AVAILABILITY}

The environmental dataset generated for this study can be found at PANGEA (https://doi.pangaea.de/10.1594/PANGAEA. 889977) and sequencing data are stored at the ENA (accession number: PRJEB26997).

\section{AUTHOR CONTRIBUTIONS}

JB, HG, MI, and AG conceived and designed the study. JB, TH, and $\mathrm{GK}$ performed the field and lab work. JB, TH, and $\mathrm{CH}$ performed the data analyses. JB wrote the manuscript. $\mathrm{HG}, \mathrm{CH}$, $\mathrm{MI}, \mathrm{GK}$, and AG contributed to the final manuscript.

\section{FUNDING}

This work was funded by the DFG (GR1540/28-1 and IV124/3-1), BMBF (01DG12073B), HGF Young Investigator Group SeaPump

\section{REFERENCES}

Acinas, S. G., Antón, J., and Rodríguez-Valera, F. (1999). Diversity of freeliving and attached bacteria in offshore western Mediterranean waters as depicted by analysis of genes encoding 16S rRNA. Appl. Environ. Microbiol. 65, 514-522.

Arístegui, J., Barton, E. D., Álvarez-Salgado, X. A., Santos, A. M. P., Figueiras, F. G., Kifani, S., et al. (2009). Sub-regional ecosystem variability in the Canary current upwelling. Prog. Oceanogr. 83, 33-48. doi: 10.1016/j.pocean.2009.07.031

Azam, F., Fenchel, T., Field, J., Gray, J., Meyer-Reil, L., and Thingstad, F. (1983). The ecological role of water-column microbes in the sea. Mar. Ecol. Prog. Ser. 10, 257-263. doi: 10.3354/meps010257

Azam, F., and Malfatti, F. (2007). Microbial structuring of marine ecosystems. Nat. Rev. 5, 782-791. doi: 10.1038/nrmicro1747

Bennke, C. M., Reintjes, G., Schattenhofer, M., Ellrott, A., Wulf, J., Zeder, M., et al. (2016). Modification of a high-throughput automatic microbial cell enumeration system for shipboard analyses. Appl. Environ. Microbiol. 82, 32893296. doi: 10.1128/AEM.03931-15

Bolger, A. M., Lohse, M., and Usadel, B. (2014). Trimmomatic: a flexible trimmer for Illumina sequence data. Bioinformatics 30, 2114-2120. doi: 10 . 1093/bioinformatics/btu170

Bory, A. J. M., and Newton, P. P. (2000). Transport of airborne lithogenic material down through the water column in two contrasting regions of the eastern subtropical north atlantic ocean. Glob. Biogeochem. Cycles 14, 297-315.

Carpenter, E., and Price, C. (1976). Marine oscillatoria (Trichodesmium): explanation for aerobic nitrogen fixation without heterocysts. Science 191, 1278-1280. doi: 10.1126/science.1257749

Carr, M.-E. (2002). Estimation of potential productivity in eastern boundary currents using remote sensing. Deep Res. Part II Top. Stud. Oceanogr. 49, 59-80. doi: 10.1016/S0967-0645(01)00094-7

Chao, A., Gotelli, N. J., Hsieh, T. C., Sander, E. L., Ma, K. H., Colwell, R. K., et al. (2014). Rarefaction and extrapolation with Hill numbers: a framework for sampling and estimation in species diversity studies. Ecol. Monogr. 84, 45-67. doi: 10.1890/13-0133.1

Cullen, J. J. (2015). Subsurface chlorophyll maximum layers: enduring enigma or mystery solved? Ann. Rev. Mar. Sci. 7, 207-239. doi: 10.1146/annurev-marine010213-135111

Dafner, E. V., and Wangersky, P. J. (2002). A brief overview of modern directions in marine DOC studies Part IIFor Part I see ref. 52.-Recent progress in marine DOC studies. J. Environ. Monit. 4, 55-69. doi: 10.1039/b107279j

Datta, M. S., Sliwerska, E., Gore, J., Polz, M., and Cordero, O. X. (2016). Microbial interactions lead to rapid micro-scale successions on model marine particles. Nat. Commun. 7:11965. doi: 10.1038/ncomms11965
"Seasonal and regional food web interactions with the biological pump" (VH-NG-1000), and by the Leibniz Association (SAW2015-ZMT-4).

\section{ACKNOWLEDGMENTS}

The authors thank the captain, crew, and other scientists aboard of METEOR for their help during the M129 cruise. They would like to especially acknowledge Thilo Klenz and Wiebke Martens (GEOMAR) for their CTD measurements and the provision of the resulting data.

\section{SUPPLEMENTARY MATERIAL}

The Supplementary Material for this article can be found online at: https://www.frontiersin.org/articles/10.3389/fmicb. 2018.02836/full\#supplementary-material

DeLong, E. F., Franks, D. G., and Alldredge, A. L. (1993). Phylogenetic diversity of aggregate-attached marine bacterial assemblages. Limnol. Oceanogr. 38, 924-934. doi: 10.4319/lo.1993.38.5.0924

Diepenbroek, M., Glöckner, F. O., Grobe, P., Güntsch, A., Huber, R., König-Ries, B., et al. (2014). "Towards an integrated biodiversity and ecological research data management and archiving platform: the german federation for the curation of biological data (GFBio ). Inform. 2014 - big data komplexität meistern," in Proceedings of the GI-Edition: Lecture Notes Informatics, eds E. Plödereder, L. Grunske, E. Schneider, and D. Ull (Bonn: Köllen Verlag), 1711-1724.

Dixon, J. L., Sargeant, S., Nightingale, P. D., and Colin Murrell, J. (2013). Gradients in microbial methanol uptake: productive coastal upwelling waters to oligotrophic gyres in the Atlantic Ocean. ISME J. 7, 568-580. doi: 10.1038/ ismej.2012.130

Enke, T. N., Leventhal, G. E., Metzger, M., Saavedra, J. T., and Cordero, O. X. (2018). Microscale ecology regulates particulate organic matter turnover in model marine microbial communities. Nat. Commun. 9:2743. doi: 10.1038/ s41467-018-05159-8

Eppley, R. W., Swift, E., Redalje, D. G., Landry, M. R., and Haas, L. W. (1988). Subsurface chlorophyll maximum in August-September 1985 in the CLIMAX area of the North Pacific. Mar. Ecol. Ser. 42, 289-301. doi: 10.3354/meps042289

Fischer, G., Karakas, G., Blaas, M., Ratmeyer, V., Nowald, N., Schlitzer, R., et al. (2009). Mineral ballast and particle settling rates in the coastal upwelling system off NW Africa and the South Atlantic. Int. J. Earth Sci. 98, 281-298. doi: 10.1007/s00531-007-0234-7

Fischer, G., Romero, O., Merkel, U., Donner, B., Iversen, M., Nowald, N., et al. (2016). Deep ocean mass fluxes in the coastal upwelling off Mauritania from 1988 to 2012: variability on seasonal to decadal timescales. Biogeosciences 13, 3071-3090. doi: 10.5194/bg-13-3071-2016

Gier, J., Löscher, C. R., Dale, A. W., Sommer, S., Lomnitz, U., and Treude, T. (2017). Benthic dinitrogen fixation traversing the oxygen minimum zone off Mauritania (NW Africa). Front. Mar. Sci. 4:390. doi: 10.3389/fmars.2017.00390

Gram, L., Grossart, H., Schlingloff, A., and Kiørboe, T. (2002). Possible quorum sensing in marine snow bacteria: production of acylated homoserine lactones by roseobacter strains isolated from marine snow possible quorum sensing in marine snow bacteria?: production of acylated homoserine lactones by roseobacter strai. Appl. Environ. Microbiol. 68, 4111-4116. doi: 10.1128/AEM. 68.8.4111

Grasshoff, K., Kremling, K., Ehrhardt, M., Anderson, L. G., Andreae, M., Behrends, B., et al. (eds) (1999). Methods of Seawater Analysis. Hoboken, NJ: Wiley, 1-600. doi: 10.1002/9783527613984

Grossart, H. P. (2010). Ecological consequences of bacterioplankton lifestyles: changes in concepts are needed. Environ. Microbiol. Rep. 2, 706-714. doi: 10. $1111 /$ j.1758-2229.2010.00179.x 
Grossart, H. P., Levold, F., Allgaier, M., Simon, M., and Brinkhoff, T. (2005). Marine diatom species harbour distinct bacterial communities. Environ. Microbiol. 7, 860-873. doi: 10.1111/j.1462-2920.2005. 00759.x

Hanson, C. A., Fuhrman, J. A., Horner-Devine, M. C., and Martiny, J. B. H. (2012). Beyond biogeographic patterns: processes shaping the microbial landscape. Nat. Rev. Microbiol. 10, 497-506. doi: 10.1038/nrmicro2795

Hassenrück, C., Fink, A., Lichtschlag, A., Tegetmeyer, H. E., De Beer, D., and Ramette, A. (2016). Quantification of the effects of ocean acidification on sediment microbial communities in the environment: the importance of ecosystem approaches. FEMS Microbiol. Ecol. 92, 1-12. doi: 10.1093/femsec/ fiw027

Hollibaugh, J. T., Wong, P. S., and Murrell, M. C. (2000). Similarity of particleassociated and free-living bacterial communities in northern San Francisco Bay. California. Aquat. Microb. Ecol. 21, 103-114. doi: 10.3354/ame02 1103

Irwin, A. J., Finkel, Z. V., Schofield, O. M. E., and Falkowski, P. G. (2006). Scaling-up from nutrient physiology to the size-structure of phytoplankton communities. J. Plankton Res. 28, 459-471. doi: 10.1093/plankt/fb i148

Iversen, M. H., Nowald, N., Ploug, H., Jackson, G. A., and Fischer, G. (2010). DeepSea research I High resolution profiles of vertical particulate organic matter export off Cape Blanc, Mauritania: degradation processes and ballasting effects. Deep Res. Part I 57, 771-784. doi: 10.1016/j.dsr.2010.03.007

Kan, J., Crump, B. C., Wang, K., and Chen, F. (2006). Bacterioplankton community in chesapeake bay: predictable or random assemblages. Limnol. Oceanogr. 51, 2157-2169. doi: 10.4319/lo.2006.51.5.2157

Kegler, H. F., Lukman, M., Teichberg, M., Plass-Johnson, J., Hassenrück, C., Wild, C., et al. (2017). Bacterial community composition and potential driving factors in different reef habitats of the spermonde archipelago. Indonesia. Front. Microbiol. 8:662. doi: 10.3389/fmicb.2017.00662

Klindworth, A., Pruesse, E., Schweer, T., Peplies, J., Quast, C., Horn, M., et al. (2013). Evaluation of general 16S ribosomal RNA gene PCR primers for classical and next-generation sequencing-based diversity studies. Nucleic Acids Res. 41, 1-11. doi: $10.1093 /$ nar/gks808

Lekunberri, I., Lefort, T., Romero, E., Vázquez-Domínguez, E., RomeraCastillo, C., Marrasé, C., et al. (2010). Effects of a dust deposition event on coastal marine microbial abundance and activity, bacterial community structure and ecosystem function. J. Plankton Res. 32, 381-396. doi: 10.1093/ plankt/fbp137

Lyons, M., Ward, J., Gaff, H., Hicks, R., Drake, J., and Dobbs, F. (2010). Theory of island biogeography on a microscopic scale: organic aggregates as islands for aquatic pathogens. Aquat. Microb. Ecol. 60, 1-13. doi: 10.3354/ame01417

Lyons, M. M., and Dobbs, F. C. (2012). Differential utilization of carbon substrates by aggregate-associated and water-associated heterotrophic bacterial communities. Hydrobiologia 686, 181-193. doi: 10.1007/s10750-012-1010-7

Mahé, F., Rognes, T., Quince, C., de Vargas, C., and Dunthorn, M. (2014). Swarm: robust and fast clustering method for amplicon-based studies. PeerJ 2:e593. doi: $10.7717 /$ peerj. 593

Martin, M. (2011). Cutadapt removes adapter sequences from high-throughput sequencing reads. EMBnet. J. 17, 10-12. doi: 10.14806/ej.17.1.200

Mestre, M., Ruiz-gonzález, C., Logares, R., Duarte, C. M., and Gasol, J. M. (2018). Sinking particles promote vertical connectivity in the ocean microbiome. Proc. Natl. Acad. Sci. U.S.A. 115, 6799-6807. doi: 10.1073/pnas.180247 0115

Needham, D. M., Sachdeva, R., and Fuhrman, J. A. (2017). Ecological dynamics and co-occurrence among marine phytoplankton, bacteria and myoviruses shows microdiversity matters. ISME J. 11, 1614-1629. doi: 10.1038/ismej.2017.29

Nercessian, O., Noyes, E., Kalyuzhnaya, M. G., Lidstrom, M. E., and Chistoserdova, L. (2005). Bacterial populations active in metabolism of C 1 compounds in the sediment of lake Washington, a freshwater lake bacterial populations active in metabolism of $\mathrm{C} 1$ compounds in the sediment of Lake Washington, a freshwater lake. Society 71, 6885-6899. doi: 10.1128/AEM.71.11. 6885

Oksanen, A. J., Blanchet, F. G., Kindt, R., Legendre, P., Minchin, P. R., Hara, R. B. O., et al. (2015). Vegan: Community Ecology Package. R Package Version 2.3-0. Available at: http://r-forge.r-project.org/projects/vegan/
Ortega-Retuerta, E., Joux, F., Jeffrey, W. H., and Ghiglione, J. F. (2013). Spatial variability of particle-attached and free-living bacterial diversity in surface waters from the Mackenzie River to the Beaufort Sea (Canadian Arctic). Biogeosciences 10, 2747-2759. doi: 10.5194/bg-10-2747-2013

Ploug, H., Grossart, H.-P., Azam, F., and Jorgensen, B. B. (1999). Photosynthesis, respiration, and carbon turnover in sinking marine snow from surface waters of Southern California Bight?: implications for the carbon cycle in the ocean. Mar. Ecol. Prog. Ser. 179, 1-11. doi: 10.3354/meps179001

Pohl, C., Croot, P. L., Hennings, U., Daberkow, T., Budeus, G., Loeff, M., et al. (2011). Synoptic transects on the distribution of trace elements $(\mathrm{Hg}, \mathrm{Pb}, \mathrm{Cd}$, $\mathrm{Cu}, \mathrm{Ni}, \mathrm{Zn}, \mathrm{Co}, \mathrm{Mn}, \mathrm{Fe}$, and $\mathrm{Al}$ ) in surface waters of the Northern- and Southern East Atlantic. J. Mar. Syst. 84, 28-41. doi: 10.1016/j.jmarsys.2010.08.003

Quast, C., Pruesse, E., Yilmaz, P., Gerken, J., Schweer, T., Yarza, P., et al. (2013). The SILVA ribosomal RNA gene database project: improved data processing and web-based tools. Nucleic Acids Res. 41, 590-596. doi: 10.1093/nar/gks 1219

Raimbault, P., Coste, B., Boulhadid, M., and Boudjellal, B. (1993). Origin of high phytoplankton concentration in deep chlorophyll maximum (DCM) in a frontal region of the Southwestern Mediterranean Sea (algerian current). Deep Sea Res. Part I Oceanogr. Res. Pap. 40, 791-804. doi: 10.1016/0967-0637(93) 90072-B

R-Core-Team (2015). R: A Language and Environment for Statistical Computing. Vienna: R-Core-Team.

Rieck, A., Herlemann, D. P. R., Jürgens, K., and Grossart, H. P. (2015). Particleassociated differ from free-living bacteria in surface waters of the baltic sea. Front. Microbiol. 6:1297. doi: 10.3389/fmicb.2015.01297

Schmidt, T. M., Delong, E. F., and Pace, N. R. (1991). Analysis of a marine picoplankton community by $16 \mathrm{~S}$ rRNA gene cloning and sequencing. J. Bacteriol. 173, 4371-4378. doi: 10.1128/jb.173.14.4371-4378.1991

Schneider, T., Bischoff, T., and Haug, G. H. (2014). Migrations and dynamics of the intertropical convergence zone. Nature 513, 45-53. doi: 10.1038/nature13636

Schütte, F., Brandt, P., and Karstensen, J. (2016). Occurrence and characteristics of mesoscale eddies in the tropical northeastern Atlantic Ocean. Ocean Sci. 12, 663-685. doi: 10.5194/os-12-663-2016

Stocker, R. (2012). Marine microbes see a sea of gradients. Science 338, 628-633. doi: 10.1126/science. 1208929

Sunagawa, S., Coelho, L. P., Chaffron, S., Kultima, J. R., Labadie, K., Salazar, G., et al. (2015). Structure and function of the global ocean microbiome. Science 348, 1261359-1261359. doi: 10.1126/science.1261359

Thiele, S., Fuchs, B. M., Amann, R., and Iversen, M. H. (2015). Colonization in the photic zone and subsequent changes during sinking determine bacterial community composition in marine snow. Appl. Environ. Microbiol. 81, $1463-$ 1471. doi: 10.1128/AEM.02570-14

Tomitani, A., Knoll, A. H., Cavanaugh, C. M., and Ohno, T. (2006). The evolutionary diversification of cyanobacteria: molecular-phylogenetic and paleontological perspectives. Proc. Natl. Acad. Sci. U.S.A. 103, 5442-5447. doi: 10.1073/pnas.0600999103

Toribio, A., Alako, B., Amid, C., Cerdeño-Tarrága, A., Clarke, L., Cleland, I., et al. (2017). The European nucleotide archive in 2017. Nucleic Acids Res. 45, D36-D40. doi: 10.1093/nar/gkx1125

Warnes, A. G. R., Bolker, B., Bonebakker, L., Huber, W., Liaw, A., Lumley, T., et al. (2016). Package 'gplots.' Various R Programming Tools for Plotting Data. $R$ Package Version 3.0. 1.

Whitman, W. B., Coleman, D. C., and Wiebe, W. J. (1998). Perspective prokaryotes: the unseen majority. Proc. Natl. Acad. Sci. U.S.A. 95, 6578-6583.

Williams, T. J., Long, E., Evans, F., Demaere, M. Z., Lauro, F. M., Raftery, M. J., et al. (2012). A metaproteomic assessment of winter and summer bacterioplankton from Antarctic Peninsula coastal surface waters. ISME J. 6, 1883-1900. doi: 10.1038/ismej.2012.28

Yawata, Y., Cordero, O. X., Menolascina, F., Hehemann, J.-H., Polz, M. F., and Stocker, R. (2014). Competition-dispersal tradeoff ecologically differentiates recently speciated marine bacterioplankton populations. Proc. Natl. Acad. Sci. U.S.A. 111, 5622-5627. doi: 10.1073/pnas.1318943111

Yilmaz, P., Kottmann, R., Field, D., Knight, R., Cole, J. R., Amaral-Zettler, L., et al. (2011). Minimum information about a marker gene sequence (MIMARKS) and minimum information about any (x) sequence (MIxS) specifications. Nat. Biotechnol. 29:415. doi: 10.1038/nbt.1823 
Yung, C.-M., Ward, C. S., Davis, K. M., Johnson, Z. I., and Hunt, D. E. (2016). Diverse and temporally-variable particle-associated microbial communities are insensitive to bulk seawater environmental parameters. Appl. Environ. Microbiol. 82, AEM.395-AEM.316. doi: 10.1128/AEM.00395-16

Zhang, J., Kobert, K., Flouri, T., and Stamatakis, A. (2014). PEAR: a fast and accurate Illumina Paired-End reAd mergeR. Bioinformatics 30, 614-620. doi: 10.1093/bioinformatics/btt593

Zhang, Y., Xiao, W., and Jiao, N. (2016). Linking biochemical properties of particles to particle- attached and free-living bacterial community structure along the particle density gradient from freshwater to open ocean. J. Geophys. Res. G Biogeosci. 121, 2261-2274. doi: 10.1002/2016JC011790.Received
Conflict of Interest Statement: The authors declare that the research was conducted in the absence of any commercial or financial relationships that could be construed as a potential conflict of interest.

Copyright (อ) 2018 Bachmann, Heimbach, Hassenrück, Kopprio, Iversen, Grossart and Gärdes. This is an open-access article distributed under the terms of the Creative Commons Attribution License (CC BY). The use, distribution or reproduction in other forums is permitted, provided the original author(s) and the copyright owner(s) are credited and that the original publication in this journal is cited, in accordance with accepted academic practice. No use, distribution or reproduction is permitted which does not comply with these terms. 